\title{
BMJ Open National medical expenditures by smoking status in American adults: an application of Manning's two-stage model to nationally representative data
}

\author{
David I Swedler, ${ }^{1}$ Ted R Miller, ${ }^{1,2}$ Bina Ali, ${ }^{1}$ Geetha Waeher, ${ }^{1}$ Steven L Bernstein ${ }^{3}$
}

To cite: Swedler DI, Miller TR, Ali B, et al. National medical expenditures by smoking status in American adults: an application of Manning's two-stage model to nationally representative data. BMJ Open 2019;9:e026592. doi:10.1136/ bmjopen-2018-026592

- Prepublication history for this paper is available online. To view these files please visit the journal online (http://dx.doi org/10.1136/bmjopen-2018026592).

Received 12 September 2018

Revised 11 June 2019

Accepted 12 June 2019

Check for updates

(c) Author(s) (or their employer(s)) 2019. Re-use permitted under CC BY-NC. No commercial re-use. See rights and permissions. Published by BMJ.

${ }^{1}$ Pacific Institute for Research and Evaluation, Calverton,

Maryland, USA

${ }^{2}$ School of Public Health, Curtin University, Perth, Western

Australia, Australia

${ }^{3}$ Department of Emergency

Medicine; Department of Health

Policy, Yale University, New

Haven, Connecticut, USA

Correspondence to

Dr David I Swedler;

dswedler@pire.org

\section{ABSTRACT}

Objectives To assess the medical expenditures of American adults by their smoking status - Current, Former or Never smokers. We update these expenditures through 2015 controlling for personal characteristics and medical history and assess the impact of years-since-quitting and decade of life.

Setting and participants Weighted sample of American adults, 2011-2015. The linked National Health Interview Survey (NHIS) and Medical Expenditure Panel Survey (MEPS) are annual weighted representations of approximately 250 million adults. Sampling of NHIS is multistage with data collected throughout the year.

Primary outcome measures Using data from NHIS and MEPS, we collected demographic data, self-reported medica history and current smoking status. Smoking status was designated as Never, Current and Former, along with yearssince-quitting. Total medical expenditures were collected from MEPS for 2011-2015. We used Manning's two-part model to estimate average expenditures per individual and marginal costs for individuals at all levels of smoking status. Results American adults averaged US\$4830 in average medical expenditures. Never smokers (US\$4360, 95\% Cl 4154.3 to 4566.3), had lower expenditures than Current (US\$5244, 95\% Cl 4707.9 to 5580.3) and Former (US\$5590, $95 \% \mathrm{Cl} 5267.4$ to 5913.5) smokers. Cl for Current and Former smokers overlapped. Results were similarly significant when controlling for disease history. Years-sincequitting did not affect expenditures. In each decade of adult life, Former smokers had the highest annual medical expenditures, followed by Current and then Never smokers. Conclusions We updated annual medical expenditures during the Affordable Care Act era by smoking status using the current best practice model. While we identify Former smokers as having higher medical expenditures than Current smokers, we do not examine how care-seeking behaviour varies between levels of each risk factor.

\section{INTRODUCTION}

It is well established that smoking can lead to medical conditions requiring acute and chronic treatment. ${ }^{1}$ Accurate marginal costs for medical risk factors are important when conducting benefit-cost analyses for health risk behaviour interventions. ${ }^{2-4}$ The most recent

\section{Strengths and limitations of this study}

- By using data from 2011 to 2015, this is the first study to report medical expenditure by smoking status while major provisions of the Affordable Care Act took effect.

- We use the gold standard two-part model developed by Manning to estimate medical expenditures from the Medical Expenditure Panel Survey and National Health Interview Survey.

- We analysed medical expenditures for Current smokers and Former smokers-both separately and combined-across decades of life

- Although we controlled for history of comorbidities, the data do not contain any information on reason for quitting among former smokers.

- The cost differences observed incorporate any differences between the groups in care-seeking for conditions unrelated to smoking.

national estimates of medical expenditures by smoking status have only considered a binary smoking variable: current smokers versus current non-smokers. ${ }^{56}$ Further, none of these national studies have analysed medical expenditure data more recently than 2011. Since that time, major reforms have been implemented to the medical care systems in the USA. ${ }^{7}$

A series of state-level analyses by Max and colleagues $^{8-10}$ described medical costs in California by current, former and never smokers. The California studies used the attributable fraction (AF) method to allocate medical expenditures. In their review of the AF method, Rockhill and colleagues define $\mathrm{AF}$ and similarly phrased terms to be 'the proportion of disease risk in a population that can be attributed to the causal effects of a risk factor or set of factors,' (p. 15) ${ }^{11}$ Rockhill et al find that the AF method has limitations, including that it is constrained by how accurately costs are allocated among diagnoses and by the availability of accurate AFs that are not confounded by co-occurring 
risk factors. ${ }^{11}$ The negative outcomes that smokers experience vary widely in nature and timing. Importantly, the method does not measure the SE for the mean estimated cost per risk taker. ${ }^{12}$

In summary, the $\mathrm{AF}$ method has too much uncertainty in risk factor allocation as well as calculation of SE. In analysing the costs of medical conditions, the health economics literature has largely shifted from this $\mathrm{AF}$ method to analyses of annual per capita medical spending of people with the condition relative to a comparison group. ${ }^{13-16}$ This approach, pioneered by Willard Manning, ${ }^{17}$ captures both mean and SE and it accounts for complications that may not be coded to the underlying condition, that is, these equations take a more holistic view of medical care and expenditures associated with risk factors' coefficients than would a process seeking to attribute specified treatment costs to specified factors. It allows that medical visits for conditions related to the behavioural risk factors may displace other medical care that might be sought if an individual did not have a given risk factor. For example, a doctor who is scheduling quarterly visits to manage diabetes is unlikely to separately schedule the annual well-care visit recommended for a healthier patient. That well-care visit gets coded as a chronic care visit even though it may not raise annual medical spending. ${ }^{18}$

While the Manning model is now the gold standard for working with skewed outcomes like medical spending, it is an imperfect tool. Although it statistically assigns costs to given risk factors or medical conditions, it does not tell us the 'why' behind each individual medical encounter or expense. Medical spending is influenced by care-seeking behaviour. Smokers may avoid visiting the doctor because it is uncomfortable to report their continued smoking behaviour or tedious to hear the doctor urge them to change. ${ }^{19}$ Health consciousness and associated use of preventive care may be below average for people who engage in risky behaviour. Furthermore, drinking heavily may be a symptom of life management issues that reduce care-seeking. Those differences in health management may mask the impacts of risk behaviour on medical spending.

\section{Purpose}

This study updates the national estimates during the implementation of many major provisions of the Patient Protection and Affordable Care Act (ACA) for annual medical expenditures of adult Americans by their current smoking status. We examine medical expenditure data for 20112015 and apply the cutting-edge two-stage Manning model to more accurately assess error around mean expenditures.

\section{METHODS}

\section{Data collection}

We analysed data on smoking status from the National Health Interview Survey (NHIS).$^{20}$ NHIS is an annual, cross-sectional survey designed to monitor health and behaviours of civilian, non-institutionalised Americans through a nationally representative sample. The Medical Expenditure Panel Survey (MEPS) tracks a nationally representative subsample of NHIS participants for 24 months starting in the year after their NHIS interview. MEPS collects five rounds of data per respondent on healthcare visits and expenditures. ${ }^{21}$ It captures all payments for care, regardless of source, and models costs for visits without payment data including charity care and visits bundled into capitated care. We used 2011-2015 MEPS data on total medical expenditures from the individual perspective for adults 18 years and older and the corresponding NHIS 2009-2014 data. Annual medical expenditures were inflated to 2015 US dollars (USD) using the Personal Consumption Expenditures-Medical Care. We linked data from MEPS and NHIS via the Agency for Healthcare Quality Data Center, as Xu et a $\tilde{\varphi}$ did in their analyses of smoking costs. ${ }^{6}$ Because our use of the publicly available data adhered to the government's privacy restrictions, the project was given an exemption by the Institutional Review Board of the Pacific Institute for Research and Evaluation prior to data analysis.

Smoking status was identified through the NHIS Supplemental Adult Questionnaire (SAQ). Like earlier studies, we identified Ever smokers as participants who smoked at least 100 cigarettes in their lifetimes. We defined all others as Never smokers. ${ }^{6}$ Ever smokers were further subdivided into those who reported quitting smoking, Former smokers, versus those who did not report quitting, Current smokers. ${ }^{8-10}$ For Former smokers, we also identified years-since-quitting.

To conduct regressions, we included the following demographic and behavioural characteristics: age, sex, race/ethnicity, marital status, total family income, family size, employment status, marital status, self-reported binge drinking status, body mass index (BMI), recent pregnancy, education level, employment and insurance data from MEPS. Age was employed as a continuous variable in the main analyses and divided into 10-year blocks in the age-specific sensitivity analysis. Binge drinking data were also obtained from the SAQ, which used the accepted binge drinking definition of men having five or more drinks and women having four or more drinks. Those participants who indicated that they had 12 or more instances of binge drinking in the past year were categorised as frequent binge drinkers, and those who had 1-11 instances were categorised as infrequent binge drinkers. BMI data were calculated from self-reported weight and height in the NHIS. We dichotomised BMI into obese for those with a BMI of $30 \mathrm{~kg} / \mathrm{m}^{2}$ or greater, and not obese for those with lower BMI. We refer to these variables collectively as personal characteristics.

NHIS and MEPS had data on self-reported diagnosis history for various diseases. Using data from both databases, we generated dichotomous variables for whether a participant had ever been diagnosed with the following diseases: asthma, arthritis, any cancer, cardiovascular diseases (including angina, coronary heart disease, myocardial infarction or stroke), diabetes and emphysema. 
NHIS had data on chronic obstructive pulmonary disease (COPD) available for 2013 through 2015 MEPS panels. From MEPS, we obtained scores for the Short Form 12 to measure quality of life, ${ }^{22}$ the Personal Health Questionnaire metric for depression ${ }^{23}$ and the Kessler 6 questionnaire for mental illness. ${ }^{24}$ From these variables, we were able to code a partial list of comorbidities that Elixhauser and colleagues ${ }^{25}$ suggest controlling for when using administrative medical data.

\section{Regression analysis}

We used the two-stage model approach developed by Manning and $\mathrm{Basu}^{17}$ to model discrete-continuous outcomes. The first regression in this method models whether or not an individual had any medical expenditures in the given year. Then, the second model estimates the costs for individuals who the first model predicted had any costs. We used an ordinary least squares logistic probit regression in the first step, followed by a generalised linear model with a generalised gamma distribution and $\log$ link in the second stage. We used the Stata twopm command developed by Belotti and colleagues to execute the two models. ${ }^{26}$ The twopm command allowed us to use the survey weights provided by the Agency for Healthcare Research and Quality (AHRQ). Data were collected and merged using SAS V.9.4 analytical software (SAS Institute, Cary, North Carolina, USA). Data management was performed in SAS and Stata IC V.15 (Stata Corp, College Station, Texas, USA). All data analyses were conducted using Stata.

Our main regression model (model 1) included personal characteristics and current smoking status. We experimented with including BMI in the model; however, the variable had near $50 \%$ missingness, so we excluded it from our final model (Further sensitivity analysis indicated that body mass had negligible impact on estimated expenditures by smoking status). We added the disease history to the two-stage model (model 2). Finally, because COPD comorbidity was only available for the last 3 years of the study, we excluded COPD and re-ran the model on all 5 years of the study period. Because controlling for this comorbidity did not noticeably affect the estimates by smoking status, we chose to report estimates based on 5 years of data, thus increasing our power to probe costs among subgroups. We further expanded model 2 to include data on years-since-quitting for Former smokers at 1-year, 2-year and 5-year thresholds. Because prevalence of these risk factors changes over the life course, we also examined the marginal effects of smoking on medical expenditures by decade of adult life. ${ }^{26}$ Non-overlapping confidence intervals (CI) indicated statistically significant differences.

\section{RESULTS}

An average of 19.7 million adults self-identified as Current smokers in the USA from 2011 to 2015. The proportion of current smokers decreased over the study period, to approximately 17.5 million adults in 2015. An average of 43.6 million adults in the USA were Ever smokers. The proportion of former smokers increased through decades of life, peaking over $22 \%$ for those older than 70 years old. Table $1 \mathrm{a}$ and $\mathrm{b}$ describe smoking status by study year and decade of life, respectively. Among the 23.9 million Former smokers, only $4.3 \%$ quit within the prior year, $8.7 \%$ quit within the prior 2 years and $24.4 \%$ quit within the 5 years prior to the survey.

Table 2 displays the costs for American adults in 2011-2015 by smoking status. In model 1, mean annual medical expenditures for US adults were US $\$ 4830$. Costs for adult Never smokers were below the national average (US\$4360). Former smokers had the highest annual medical expenses, US $\$ 5590$ (28\% increase over Never smokers). Although Current smokers had lower average costs than Former smokers at US\$5144 (18\% increase over Never smokers), the $95 \%$ CIs overlap for Current and Former smokers. If we combine Current and Former smokers into Ever smokers and re-run model 1, the average costs for someone who has ever smoked is US $\$ 5400$ (95\% CI 5142 to 5659 ).

Table 1 Prevalence of smoking by year of Medical Expenditure Panel Survey data collection (a) and decade of age (b)

(a) Smoking status by year of medical expenditure

\begin{tabular}{lcccccr}
\hline & $\mathbf{2 0 1 1}$ & $\mathbf{2 0 1 2}$ & $\mathbf{2 0 1 3}$ & $\mathbf{2 0 1 4}$ & $\mathbf{2 0 1 5}$ & $\mathbf{n}$ \\
\hline Current & $7.7 \%$ & $8.7 \%$ & $8.4 \%$ & $7.9 \%$ & $7.3 \%$ & 19716719 \\
Never & $83.7 \%$ & $81.6 \%$ & $81.6 \%$ & $81.6 \%$ & $82.4 \%$ & 206862703 \\
Former & $8.6 \%$ & $9.7 \%$ & $10.0 \%$ & $10.5 \%$ & $10.3 \%$ & 23900571 \\
\hline
\end{tabular}

(b) Smoking status by decade of life

\begin{tabular}{lrrrrrr}
\hline & $\mathbf{1 8 - 3 0}$ & $\mathbf{3 1 - 4 0}$ & $\mathbf{4 1 - 5 0}$ & $\mathbf{5 1 - 6 0}$ & $\mathbf{6 1 - 7 0}$ & $\mathbf{7 0 +}$ \\
\hline Current & $6.8 \%$ & $9.8 \%$ & $9.2 \%$ & $9.6 \%$ & $7.4 \%$ & $4.4 \%$ \\
Never & $90.5 \%$ & $83.2 \%$ & $83.8 \%$ & $79.8 \%$ & $76.8 \%$ & $73.3 \%$ \\
Former & $2.7 \%$ & $7.0 \%$ & $7.1 \%$ & $10.6 \%$ & $15.7 \%$ & $22.3 \%$ \\
\hline
\end{tabular}

Average participants in each category were developed using survey weights. 
Table 2 Results of the two-part model for smoking status on mean medical expenditures per year, 2011-2015, in 2015 US dollars

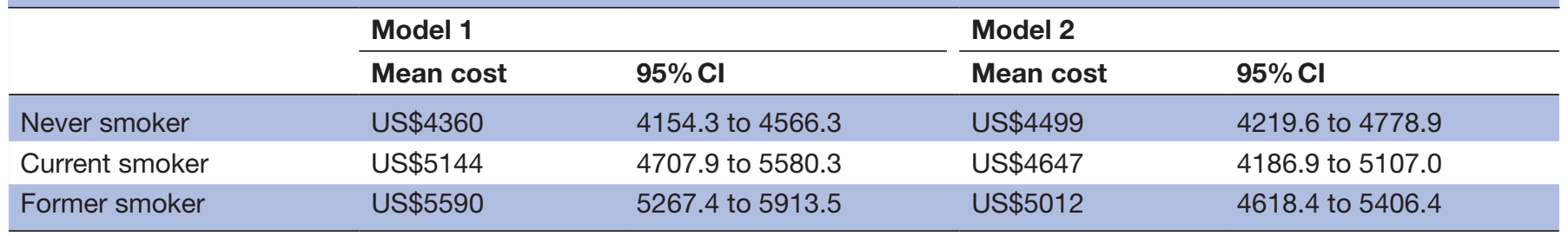

Model 1 included smoking and personal characteristics only. ${ }^{*}$ Model 2 included personal characteristics, smoking and comorbidities. $\dagger$ ${ }^{*}$ Covariates included in model 1 were age (continuous), gender, race/ethnicity (White, African American, Asian, Hispanic origin, Other), education (No high school degree, High school or some college, At least college graduate), marital status (Single/Never married, Current married, Widowed/Divorced/Separated), Pregnancy in the prior year, employment status (Unemployed, Employed, Full-time student, Never worked, Retired), logged-total family income, insurance status (Private, Any public insurance (under age 65), Medicare/Medicaid+, Uninsured), family size, year dummy variables, any binge drinking in the prior year and BMI (Normal weight or Underweight, Overweight or Obese). †In addition to the variables in model 1, a history of the following conditions were added to model 2: any cancer, diabetes, asthma, arthritis, cardiovascular disease (angina, coronary heart disease, myocardial infarction or stroke), emphysema, quality of life calculated from Short Form 12, depression calculated from the Personal Health Questionnaire and mental illness from the Kessler 6 questionnaire.

In table 3 , a sensitivity analysis for model 2 that includes years-since-quitting for Former smokers does not find a direct relationship between time since smoking cessation and medical expenditures. The mean expenditures by cessation period have small differences, and the $95 \%$ CIs greatly overlap. Table 4 identifies displays how medical expenditures vary across decades of life by smoking status. The $95 \%$ CIs for Never smokers in table 4 do not contain the estimate for Former smokers at each decade. The CIs for Former smokers do not contain the estimate for Never smokers at all decades except for age 20. The 95\% CIs for Current smokers at each decade include both the Never and Former smoker estimates, and the CIs for Never and Former smokers include the estimate for Current smokers.

Multiplying costs by average number of smokers for 2011-2015, Current smokers incurred US $\$ 101.4$ billion in average annual medical expenses (95\% CI 92.8 billion to 110.0 billion), US $\$ 15$ billion above the costs for a demographically comparable number of Never smokers. Former smokers incurred an average of $\$ 133.6$ billion in annual medical expenditures (95\% CI 125.9 billion to 141.4 billion), a US $\$ 29$ billion increase over comparable Never smokers. Average annual medical expenditures for Ever smokers are US\$235.6 billion (95\% CI 224 billion to 247 billion), approximately $\$ 45$ billion above the costs for a demographically comparable number of Never smokers.

Table 3 Results of separate runs of the two-part model of mean medical expenditures for Former smokers using 1-year, 2-year and 5-year thresholds for years-since-quitting smoking in 2015 US dollars

\begin{tabular}{lll}
\hline Years since quitting & Mean & $\mathbf{9 5 \%} \mathbf{C l}$ \\
\hline 1 or fewer years & $\$ 5036$ & 3604.4 to 6646.6 \\
\hline More than 1 year & $\$ 5006$ & 4588.8 to 5422.3 \\
\hline or fewer years & $\$ 5132$ & 4035.0 to 6229.6 \\
More than 2 years & $\$ 4986$ & 4543.6 to 5429.1 \\
\hline or fewer years & $\$ 4957$ & 4182.8 to 5730.7 \\
\hline More than 5years & $\$ 5028$ & 4551.1 to 5505.2 \\
\hline
\end{tabular}

\section{DISCUSSION}

We updated the national estimates for smoking costs in American adults through 2015 using state-of-the-science economic modelling techniques. This was a period when major provisions of the ACA were being enacted, for example, state Medicaid expansion and the 'individual mandate' in 2014. ${ }^{7}$ Our estimates for annual medical expenditures for all civilian non-institutionalized adults was US $\$ 4830$ for 2011-2015, in 2015 USD. This estimate for the study period was close to Mitchell and Machlin's ${ }^{27}$ estimate of average total medical expenditures in 2015 using MEPS data (US\$4978). Our estimate for annual expenditures and marginal costs due to smoking are below similar estimates generated using the National Health Expenditure Assessment (NHEA) database. ${ }^{28} 29$ However, NHEA is more comprehensive than MEPS in capturing Medicaid costs covering institutionalised adults (including those in nursing homes), active-duty military and foreign visitors to the USA, ${ }^{29} 30$ so we expected MEPS to yield lower estimates.

We find that Former smokers have greater annual medical costs over Current and Never smokers; however, the $95 \%$ CIs overlap for Current and Former smokers in the main model. Surely, some smokers quit after diagnosis of costly health problems linked to smoking, but the cost differential narrows only slightly after controlling for major chronic conditions (many of which are linked to smoking). Especially at younger ages, quitting appears to be more likely to sort smokers by health consciousness and associated use of medical care.

Some older studies compared medical spending per capita among current, former and never smokers. Using data from the 1987 National Medical Expenditure Survey, Miller and colleagues (1999) identified higher annual medical expenditures in former smokers over current smokers. Contrasting with the national studies, two studies using local claims data ${ }^{31}$ found that medial expenditures for current and former smokers were nearly identical, with a slight spike in costs for former smokers immediately following quitting. 
Table 4 Average annual medical expenditures in 2011-2015 for American adults of selected ages by smoking status, from a two-part model including personal characteristics and disease history at each decade of life ages 20-80, in 2015 US\$.

\begin{tabular}{|c|c|c|c|c|c|c|c|c|}
\hline \multirow{3}{*}{$\begin{array}{l}\text { Smoking } \\
\text { status }\end{array}$} & \multicolumn{8}{|l|}{ Age } \\
\hline & \multicolumn{2}{|l|}{20} & \multicolumn{2}{|l|}{30} & \multicolumn{2}{|l|}{40} & \multicolumn{2}{|l|}{50} \\
\hline & Estimate & $95 \% \mathrm{Cl}$ & Estimate & $95 \% \mathrm{Cl}$ & Estimate & $95 \% \mathrm{Cl}$ & Estimate & $95 \% \mathrm{Cl}$ \\
\hline Never & US\$2743 & 2366 to 3151 & US\$3214 & 2857 to 3571 & US\$3763 & 3472 to 4054 & US $\$ 4401$ & 4160 to 4642 \\
\hline Current & US\$2909 & 2390 to 3428 & US\$3413 & 2928 to 3897 & US\$4000 & 3561 to 4438 & US\$4683 & 4284 to 5081 \\
\hline \multirow[t]{2}{*}{ Former } & US\$3208 & 2704 to 3711 & US\$3754 & 3301 to 4208 & US\$4390 & 3947 to 4783 & US\$5130 & 4776 to 5483 \\
\hline & \multicolumn{8}{|l|}{ Age } \\
\hline \multirow{2}{*}{$\begin{array}{l}\text { Smoking } \\
\text { status }\end{array}$} & \multicolumn{2}{|l|}{60} & \multicolumn{2}{|l|}{70} & \multicolumn{2}{|l|}{80} & & \\
\hline & Estimate & $95 \% \mathrm{Cl}$ & Estimate & $95 \% \mathrm{Cl}$ & Estimate & $95 \% \mathrm{Cl}$ & & \\
\hline Never & US\$5143 & 4846 to 5440 & US\$6007 & 5505 to 6508 & US\$7010 & 6184 to 7836 & & \\
\hline Current & US\$5478 & 5059 to 5897 & US\$6403 & 5839 to 6968 & US\$7479 & 6627 to 8331 & & \\
\hline Former & US $\$ 5990$ & 5574 to 6407 & US\$6990 & 6357 to 7623 & US\$8153 & 7160 to 9145 & & \\
\hline
\end{tabular}

Some current smokers may experience very high cost medical expenditures over a short period before dying (and thus not incurring any further costs), while former smokers may continue to amass lower cost medical encounters. These former smokers would be gaining up to 10 years of survival and medical expenditures over current smokers. ${ }^{33}$ Current smokers also may simply be doctor phobic, anxious to avoid yet another lecture about their smoking. The persistence and contrarian nature of our finding of higher medical expenditures in former smokers at all ages and regardless of time-since-quitting, suggests exploring the issue using qualitative methods.

We followed the methods of $\mathrm{Xu}$ and colleagues ${ }^{5}$ and Max and colleagues ${ }^{8-10}$ to identify current, former and never smokers in NHIS/MEPS data. Those studies examined AFs for medical expenditures rather than costs to individuals. The two-part model developed by Manning and colleagues has become the gold standard for estimating costs in a skewed sample, such as medical expenditures. ${ }^{1734}$ It has been used to study the impact of smoking on healthcare costs across a wide variety of databases. ${ }^{6356}$ An analysis from $\mathrm{An}^{6}$ using the two-stage model was performed on medical expenditures associated with smoking status (ever vs never) and obesity ( $<30 \mathrm{BMI}$ vs $30 \geq \mathrm{BMI}$ ) using MEPS data from 1998 to 2011. In contrast to the present study, An's estimated expenditures did not control for quit status, marital status, family income, family size or pregnancy. Our estimated cost differences between ever/never smokers and obese/non-obese individuals (data not shown) were lower than in the An study. We believe that the inclusion of quit status and additional personal characteristics in the two-stage models increases the precision of our estimate over this prior study.

\section{Limitations and strengths}

Many of the prior studies assessing the impact of behavioural risk factors on medical expenditures employ the traditional AF approach, which constructs costs from selected acute and chronic conditions related to the individual risk factors of interest. This method is appropriate unless a study echoes our aim to examine the marginal effects of the risk behaviours on costs to individuals. Using the two-part model, ${ }^{17}$ our study provides a different assessment of medical expenditures than the AF method. AF studies estimate the smoking-related medical costs incurred in treated diseases that resulted from smoking. The two-stage modelling approach instead looks at the overall medical spending of the smoking cohort. It can be strongly influenced by a difference in care-seeking propensity.

Our estimates for prevalence of smoking (9\%) are lower than those found in other surveillance studies. The Behavioural Risk Factor Surveillance System (BRFSS) identified 15\% of American adults as current smokers in 2015. ${ }^{37}$ This discrepancy between BRFSS and NHIS data may be due to different modes of data collection. While BRFSS collects data through telephone surveys, NHIS collects data via within-household, in-person interviews. Unlike NHIS, BRFSS data collection is decentralised as is the responsibility of each state health department.

The goal of this study was to update medical expenditures for smoking to 2015. It was beyond the scope of the study to assess spending by type of medical service used. With sufficient budget, doing so might have allowed us to propose more hypotheses as to why certain risks had increased costs over others, as Sturm ${ }^{38}$ did for obesity and problem drinking.

In a period of low inflation, we chose to control for inflation in our multiyear analysis of expenditures by including dummy variables for MEPS year rather than using price adjusters that assume a fixed market basket of medical services. The dummy variables should account not only for year-to-year changes in costs, but for other endogenous temporal effects. Those effects include the many policy features of 2010's ACA that went into effect from 2011 to $2015{ }^{7}$ Further analysis of the impacts of all components of the ACA on medical expenditures is warranted. 


\section{CONCLUSION}

Our data are the most recent examination of medical expenditures nationwide across current smoking status. One clear application of our estimates is in computing the medical spending foregone because behavioural risk takers have elevated risks of morbidity and mortality. Although tobacco cessation cause declines in chronic illness, early mortality and associated costs, it appears they may not decrease annual medical expenditures per survivor. That finding suggests studies of return on investment in smoking cessation that use AF-based costs may yield skewed results.

Acknowledgements The research in this paper was conducted at the CFACT Data Center, and the support of AHRQ is acknowledged. The results and conclusions in this paper are those of the authors do not indicate concurrence by AHRQ or the Department of Health and Human Services.

Contributors SLB, TRM and DIS conceived of the study. DIS, GW and TRM designed the analysis. DIS conducted the analysis. DIS and BA wrote and edited drafts of the manuscript. All authors provided input on the manuscript and approved of the final draft.

Funding Funding for this project was provided by NHLBI grant AN: 3421751 (Implementation of HIT-Enhanced Tobacco Treatment for Hospitalized Smokers) and NCl grant R01CA201873 (Optimizing Tobacco Dependence Treatment in the Emergency Department).

Competing interests None declared.

Patient consent for publication Not required.

Provenance and peer review Not commissioned; externally peer reviewed.

Data sharing statement Data are held by the United States Department of Health and Human Services. Raw data are not made available for public sharing.

Open access This is an open access article distributed in accordance with the Creative Commons Attribution Non Commercial (CC BY-NC 4.0) license, which permits others to distribute, remix, adapt, build upon this work non-commercially, and license their derivative works on different terms, provided the original work is properly cited, appropriate credit is given, any changes made indicated, and the use is non-commercial. See: http://creativecommons.org/licenses/by-nc/4.0/.

\section{REFERENCES}

1. U.S. Department of Health and Human Services. The Health Consequences of Smoking - 50 Years of Progress: A Report of the Surgeon General. Atlanta, GA: U.S: Department of Health and Human Services, Centers for Disease Control and Prevention, National Center for Chronic Disease Prevention and Health Promotion, Office on Smoking and Health, 2014.

2. Warner KE. Cost effectiveness of smoking-cessation therapies. Pharmacoeconomics 1997;11:538-49.

3. Leblanc ES, O'Connor E, Whitlock EP, et al. Effectiveness of primary care-relevant treatments for obesity in adults: a systematic evidence review for the U.S. Preventive Services Task Force. Ann Intern Med 2011;155:434-47.

4. Fleming MF, Mundt MP, French MT, et al. Brief physician advice for problem drinkers: long-term efficacy and benefit-cost analysis. Alcohol Clin Exp Res 2002;26:36-43.

5. Xu X, Bishop EE, Kennedy SM, et al. Annual healthcare spending attributable to cigarette smoking: an update. Am J Prev Med 2015;48:326-33.

6. An R. Health care expenses in relation to obesity and smoking among U.S. adults by gender, race/ethnicity, and age group: 19982011. Public Health 2015;129:29-36.

7. French MT, Homer J, Gumus G, et al. Key provisions of the patient protection and Affordable Care Act (ACA): a systematic review and presentation of early research findings. Health Serv Res 2016;51:1735-71.

8. Max W, Sung HY, Shi Y, et al. The cost of smoking in California. Nicotine Tob Res 2016;18:1222-9.

9. Max W, Rice DP, Sung HY, et al. The economic burden of smoking in California. Tob Control 2004;13:264-7.

10. Max W, Sung H-Y, Shi Y, et al. The cost of smoking in California, 2009. San Francisco, CA: Institute for Health \& Aging, University of California, San Francisco, 2014
11. Rockhill B, Newman B, Weinberg C. Use and misuse of population attributable fractions. Am J Public Health 1998;88:15-19.

12. Lavelle TA, Kent DM, Lundquist CM, et al. Patient Variability Seldom Assessed in Cost-effectiveness Studies. Med Decis Making 2018;38:487-94

13. Trogdon JG, Finkelstein EA, Hoerger TJ. Use of econometric models to estimate expenditure shares. Health Serv Res 2008;43:1442-52.

14. Tangka FK, Trogdon JG, Richardson LC, et al. Cancer treatment cost in the United States: has the burden shifted over time? Cancer 2010;116:3477-84

15. Heidenreich PA, Trogdon JG, Khavjou OA, et al. Forecasting the future of cardiovascular disease in the United States: a policy statement from the American Heart Association. Circulation 2011;123:933-44.

16. Florence CS, Zhou C, Luo F, et al. The economic burden of prescription opioid overdose, abuse, and dependence in the United States, 2013. Med Care 2016;54:901-6.

17. Manning WG, Basu A, Mullahy J. Generalized modeling approaches to risk adjustment of skewed outcomes data. J Health Econ 2005;24:465-88.

18. Jackson CA, Manning WG, Wells KB. Impact of prior and current alcohol use on use of services by patients with depression and chronic medical illnesses. Health Serv Res 1995;30:687-705.

19. Butler CC, Pill R, Stott NC. Qualitative study of patients' perceptions of doctors' advice to quit smoking: implications for opportunistic health promotion. BMJ 1998;316:1878-81.

20. National Center for Health Statistics. National Health Interview Survey. 2018. https://www.cdc.gov/nchs/nhis/index.htm

21. Agency for Healthcare Research and Quality. Medical Expenditure Panel Survey. 2018. https://meps.ahrq.gov/mepsweb/

22. Sengupta N, Nichol MB, Wu J, et al. Mapping the SF-12 to the HUI3 and VAS in a managed care population. Med Care 2004;42:927-37.

23. Arroll B, Goodyear-Smith F, Crengle $S$, et al. Validation of $P H Q-2$ and $\mathrm{PHQ}-9$ to screen for major depression in the primary care population. Ann Fam Med 2010;8:348-53.

24. Kessler RC, Barker PR, Colpe LJ, et al. Screening for serious mental illness in the general population. Arch Gen Psychiatry 2003;60:184-9.

25. Elixhauser A, Steiner C, Harris DR, et al. Comorbidity measures for use with administrative data. Med Care 1998;36:8-27.

26. Belotti F, Deb P, Manning WG, et al. Twopm: Two-Part Models. Stata J 2015;15:3-20.

27. Mitchell E, Machlin S. Concentration of health expenditures and selected characteristics of high spenders, U.S. civilian noninstitutionalized population, 2015. Statistical Brief \#506. Rockville, MD: Agency for Healthcare Research and Quality, 2017.

28. Lassman $D$, Hartman $M$, Washington $B$, et al. US health spending trends by age and gender: selected years 2002-10. Health Aff 2014;33:815-22.

29. Finkelstein EA, Trogdon JG, Cohen JW, et al. Annual medical spending attributable to obesity: payer-and service-specific estimates. Health Aff 2009;28:w822-w831.

30. Sing M, Banthin JS, Selden TM, et al. Reconciling medical expenditure estimates from the MEPS and NHEA, 2002. Health Care Financ Rev 2006;28:25-40.

31. Fishman PA, Khan ZM, Thompson EE, et al. Health care costs among smokers, former smokers, and never smokers in an HMO. Health Serv Res 2003;38:733-49.

32. Hockenberry JM, Curry SJ, Fishman PA, et al. Healthcare costs around the time of smoking cessation. Am J Prev Med 2012:42:596-601.

33. Jha P, Ramasundarahettige C, Landsman V, et al. 21st-century hazards of smoking and benefits of cessation in the United States. $N$ Engl J Med 2013;368:341-50.

34. Buntin MB, Zaslavsky AM. Too much ado about two-part models and transformation? Comparing methods of modeling Medicare expenditures. J Health Econ 2004;23:525-42.

35. Coughlan D, Yeh ST, O'Neill C, et al. Evaluating direct medical expenditures estimation methods of adults using the medical expenditure panel survey: an example focusing on head and neck cancer. Value Health 2014;17:90-7.

36. Baumeister SE, Böger CA, Krämer BK, et al. Effect of chronic kidney disease and comorbid conditions on health care costs: A 10 -year observational study in a general population. Am J Nephrol 2010;31:222-9.

37. Jamal A, King BA, Neff LJ, et al. Current cigarette smoking among adults - United States, 2005-2015. MMWR Morb Mortal Wkly Rep 2016;65:1205-11.

38. Sturm R. The effects of obesity, smoking, and drinking on medical problems and costs. Health Aff 2002;21:245-53. 
